\title{
Análise de um jogo RPG educacional produzido pelo próprio docente, auxiliado por Ferramenta de Autoria
}

\author{
Cleber Gurzynski, Marcelo da Silva Hounsell ${ }^{1}$, Avanilde Kemczinski ${ }^{12}$ \\ ${ }^{1}$ PPGCA - Programa de Pós-Graduação em Computação Aplicada e ${ }^{2}$ PPGECMT - \\ Programa de Pós-Graduação em Ensino de Ciências, Matemática e Tecnologias, \\ Universidade do Estado de Santa Catarina (UDESC), Joinville,- SC \\ clebervision@gmail.com, \\ \{marcelo.hounsell, avanilde.kemczinski\}@udesc.br
}

\begin{abstract}
To spread the use of digital videogames to classrooms it depends directly on the involvement of a subject matter specialist (in this case, a teacher). The use of an Authoring Tool (AT) might be an option to make it easier to produce videogames by teachers themselves. This paper presents an experience of building and using an educational RPG (Role Playing Game) videogame. A teacher with no knowledge on programming used the AT to conceive the videogame as a supporting tool for teaching and students used the resulting videogame and evaluated it afterwards. The resulting videogame was assessed as regular both in technical and pedagogical aspects by the students and this shows that the AT did helped the teacher.
\end{abstract}

Resumo. Ampliar o uso de jogos digitais para o contexto da sala de aula depende diretamente do envolvimento dos especialistas de conteúdo (no caso, docentes). $O$ uso de Ferramentas de Autoria (FA) se apresenta como uma opção para facilitar que o próprio docente desenvolva o jogo. Este artigo mostra a experiência de construção e uso de um jogo digital educacional do tipo RPG (Role Playing Game). Uma docente sem conhecimento de programação usou uma FA para conceber um jogo como forma de apoio ao aprendizado do conteúdo e estudantes usaram e avaliaram o jogo. O jogo resultante foi avaliado regular nos aspectos técnicos e pedagógicos pelos estudantes mostrando que a FA auxiliou a docente.

\section{Introdução}

Hoje, Jogos Sérios (JS) são um tema em ebulição no mundo acadêmico: diversas pesquisas, [Grando 1995], [Haguenauer et al. 2008], demostram melhor rendimento dos estudantes quando são utilizados jogos para auxiliar no aprendizado. Porém, utilizando os métodos tradicionais de desenvolvimento de jogos o tempo e os conhecimentos técnicos requeridos são grandes, o que eleva os custos. Uma solução para baratear os custos seria utilizar Ferramentas de Autoria (FA), o que tornaria mais ágil e simples o processo de desenvolvimento porém, segundo Pessini (2015), poucas são as FA para desenvolvimento de jogos educacionais e/ou sérios. Com base nessas informações Pessini (2015) desenvolveu a RPG4ALL, uma FA para desenvolvimento de jogos RPG digital sério. $\mathrm{O}$ foco desta FA são os professores de quaisquer disciplinas e que não tem conhecimentos na área de desenvolvimento de software, i.e., na área de programação. 
V Congresso Brasileiro de Informática na Educação (CBIE 2016)

Anais do XXVII Simpósio Brasileiro de Informática na Educação (SBIE 2016)

Esta FA é composta por Módulo de Autoria e Módulo de Execução. O Módulo de Execução é a parte da FA que se apresenta para o estudante na forma de jogo com os conteúdos e o enredo definido pelo professor no Módulo de Autoria, conforme Figura 1.

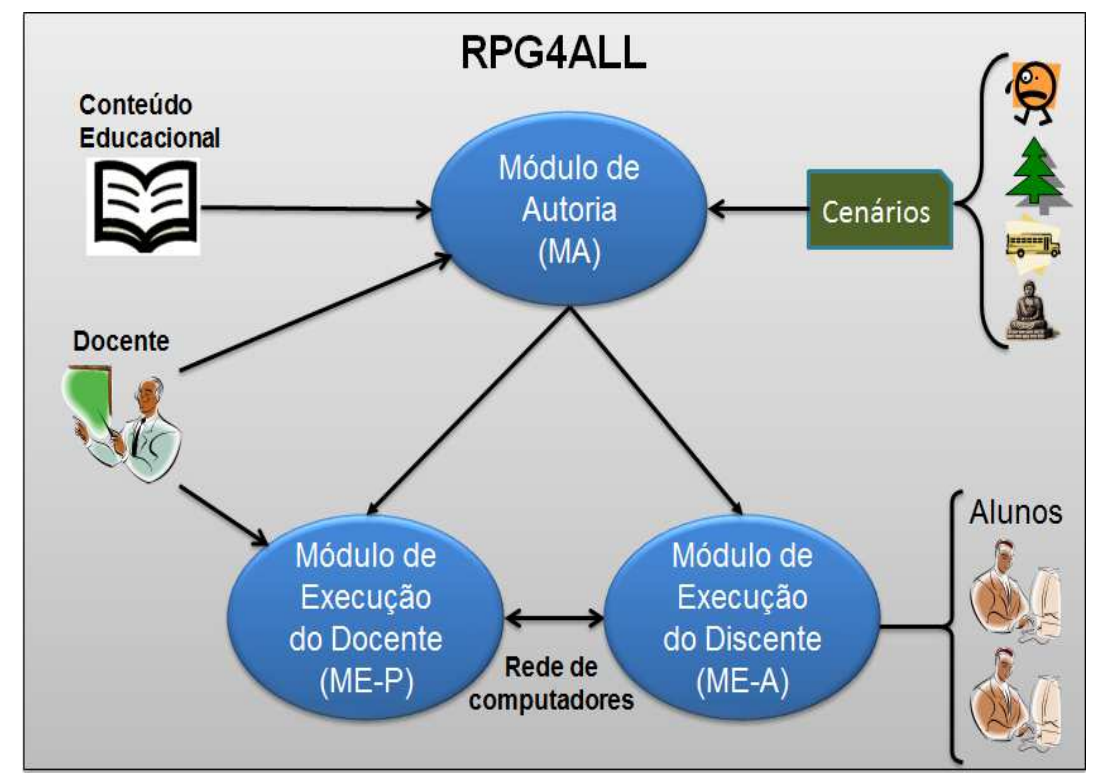

Figura 1. Ferramenta de Autoria de Jogos RPG4ALL [Pessini 2015].

O Módulo de Execução é usado pelos estudantes mas também pelo professor que pode interagir, bem como controlar, o uso do jogo pelos estudantes. Dentre alguns resultados da aplicação do RPG4ALL, a ampla maioria (91,6\%) dos professores acharam o Módulo de Autoria de fácil uso e $(66,6 \%)$ dos professores acharam o Módulo de Execução de fácil uso [Pessini 2015]. Estes dados sugerem que sim, que o professor consegue utilizar a FA para gerar um jogo digital sério mas, questiona-se se este jogo é realmente atrativo para os estudantes.

O objetivo deste artigo é avaliar o Módulo de Execução (o jogo propriamente dito) sob o ponto de vista dos estudantes (jogadores), uma vez que são estes, os usuários finais para os quais foram desenvolvidos os jogos do Módulo de Autoria. Juntamente com esta avaliação foram considerados duas versões do mesmo jogo implementadas com tecnologias gráficas diferentes cuja a evolução gráfica geraria melhor aceitação do jogo.

\section{Fundamentos}

O uso de Jogos Sérios (JS) na educação se deve ao fato de que a interação dos estudantes com o universo dos jogos ocorre cada vez mais cedo e os JS têm sido utilizados de forma crescente, explorando atividades lúdicas que possuem objetivos pedagógicos específicos com a finalidade de desenvolver o raciocínio e o aprendizado [Corrêa et al, 2008].

Neste sentido, os Jogos Digitais Sérios do gênero Role Playing Game (RPGDS) permitem que os jogadores representem papéis a partir de um cenário contextualizado vivenciando as ações dos seus personagens neste ambiente [Frias, 2009]. Araújo (2006) destaca que as atividades de ensino suportadas por RPGDS implicam no esforço do 
jogador que está emocionalmente vinculado ao resultado do jogo. Estas atividades de ensino exploram características como trabalho em grupo e aprendizado baseado em resolução de problemas [Maike e Baranauskas 2011].

Tarouco (2008) define RPG como jogo de representação de papeis e seus principais elementos como a criatividade e a cooperação. O RPG pode ser classificado em RPG digital e RPG de mesa. Em ambas as versões existem regras que definem o jogo. Mas no RPG de mesa é o mestre quem descreve o cenário do jogo, já no RPG digital o cenário e as regras do jogo são parcialmente ou totalmente controladas por um software.

Com o crescente uso de jogos para o laser tornou-se interessante a utilização de jogos com propósitos mais sérios como, por exemplo, ensinar uma matéria de maneira mais agradável pois "Os jogos nos engajam, nos atraem, geralmente sem que nos demos conta." [Tarouco 2008]. Segundo Frias (2009) o RPG é adequado para jogos onde há necessidade de vivenciar outras experiências interpretando um personagem que poderia ser um guerreiro ou até mesmo um gerente de uma empresa ou um fiscal.

A vantagem do uso de JS, como por exemplo o RPG está na possibilidade de vivenciar experiências que simulam situações reais e situações que seriam impossíveis no mundo real por questões de segurança, custos, tempo, dentre outros [Michael; Chen 2006], provendo, assim, experiências significativamente diferentes para o jogador [Gonçalves; Ferreira 2012] quando comparadas aos meios de educação e treinamento convencionais.

Schmit (2008) afirma também que o RPG estimula pessoas a formarem grupos e se encontrarem em intervalos regulares, por longos períodos de tempo, não raro atravessando madrugadas. Nestes encontros, os jogadores representam e vivenciam seus personagens, em interação com as demais, respondendo constantemente a desafios propostos pelo mestre do jogo. A necessidade de interação entre os jogadores demonstra que o RPG é um jogo baseado em comunicação, colaboração e criatividade.

Segundo [Frias 2009] o RPG é composto por: Universo Ficcional: é o espaço e tempo fictícios em que o jogo ocorre; Aventura: a aventura pode ser de curta ou longa duração e vivida individualmente ou em conjunto com outros jogadores; Trama: é onde estão os conflitos, inimigos, situações-problema e obstáculos a serem transpostos; A Narrativa: é o que determina como os personagens vão interagir entre eles e com os demais elementos do jogo; Mestre do Jogo: é um personagem dotado de capacidade de liderança e bom censo o qual conduz o processo, sendo responsável pela criação e apresentação dos elementos de jogo aos personagens sendo assim ele está jogando contra e a favor do grupo ao mesmo tempo; Personagens: são dotados de qualidades, defeitos e habilidades que vão sendo aperfeiçoadas e incrementadas ao longo do jogo. Segundo Dormans (2006), tem-se ainda os Non-Player Character (NPC) que são personagens não jogadores controlados pelo Mestre e pelas regras do jogo.

\section{RPG4ALL}

Segundo Pessini (2015), a comunidade científica tem se esforçado em reduzir a complexidade de desenvolvimento através de ferramentas que apoiem o desenvolvimento de JS [Dormans, 2012] fornecendo os meios para reduzir o custo e facilitando o processo de projeto e desenvolvimento [Zarraonandia; Díaz; Aedo 2012]. Apesar deste esforço, a introdução de jogos digitais no contexto educacional não está livre de barreiras sendo que os custos e a necessidade de conhecimento técnico é um 
V Congresso Brasileiro de Informática na Educação (CBIE 2016)

Anais do XXVII Simpósio Brasileiro de Informática na Educação (SBIE 2016)

empecilho à sua ampla adoção [Torrente et al 2011]. Neste contexto, as Ferramentas de Autoria (FA) têm sido incorporadas para facilitar e diminuir os custos do processo de desenvolvimento de JS [Mehm 2010]; [Zarraonandia; Díaz; Aedo 2012]; [Tang; Hannegham 2013].

A RPG4ALL é uma FA para desenvolvimento de JS do tipo RPG digital multiplayer, o qual o desenvolvedor (professor) não precisa ter conhecimento algum de programação ou algoritmos. Os jogos são desenvolvidos por meio de uma interface de assistente (Wizard, conforme mostra a Figura 2), em que o desenvolvedor conta com uma série de mapas, de personagens e de objetos já prontos para usar em um jogo e ainda pode importar novos objetos e personagens.

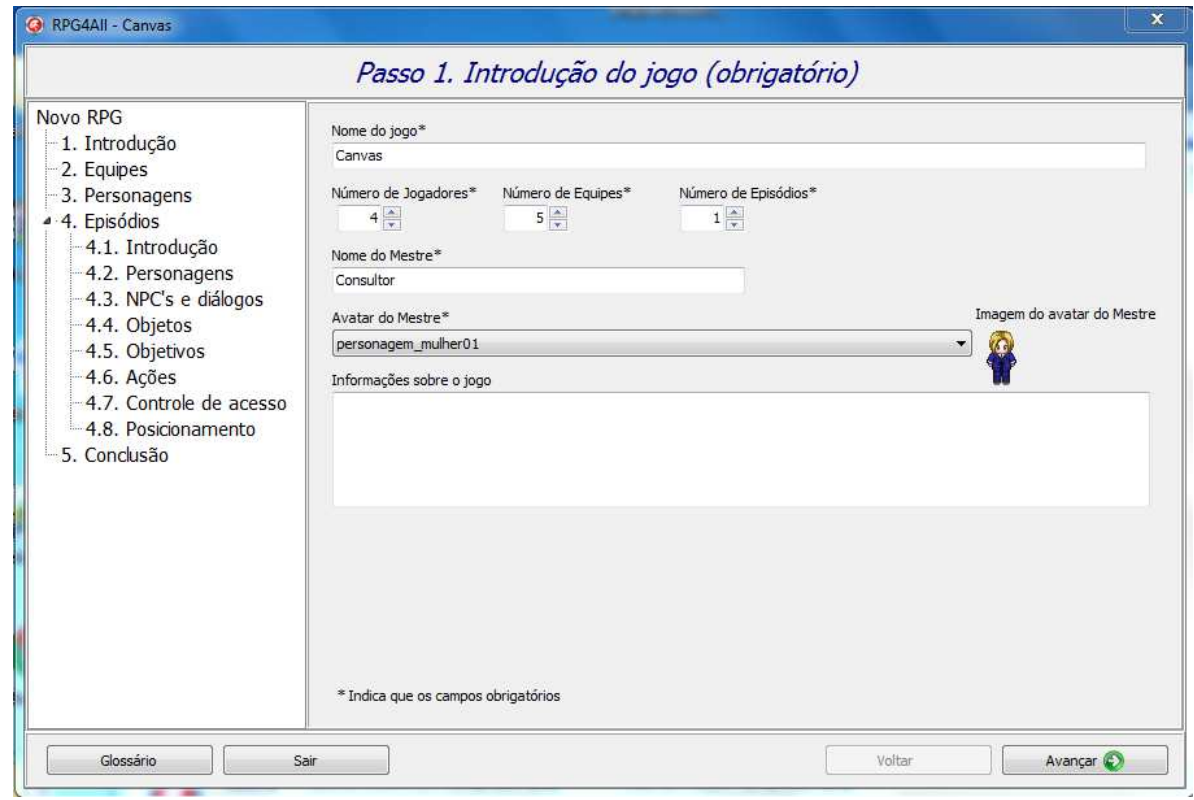

Figura 2. Interface gráfica assistente do Modulo de Autoria.

Na Figura 2 são exibidas as etapas de desenvolvimento do jogo; o professor precisa: criar a descrição do jogo, definir o número de episódios, criar uma descrição para cada episódio, definir o número de equipes, número de jogadores por equipe, definir o avatar, a descrição e quais serão os objetivos de cada personagem e de quais episódios ele vai participar, em quais equipes ele estará presente. Também são necessários definir os objetos interativos do jogo e quais objetivos estão atrelados a qual objeto.

Ao longo do trabalho, duas versões do Modulo de Execução foram concebidas: a versão 1.0, no protótipo original e; a versão 2.0 na versão final. De modo geral, as duas versões são idênticas, entretanto alguns aspectos tecnológicos são diferentes:

- Na versão 1.0, o dialogo com os NPC é via seleção de opção de menu em teclado; a arquitetura de comunicação Per-2-Per (exigindo algum conhecimento técnico do docente quanto a configuração da rede local); a Linguagem de programação usada foi Object Pascal (Ambiente Delphi); foi utilizada a IDE Rad Studio XE3 para a produção da interface gráfica (GUI - Graphical User Interface), cujo uso gratuito é limitado somente até 30 dias, e; a coleta de dados é feita de forma manual e distribuída (exigindo do docente um esforço final para copiar arquivos em cada máquina que os estudantes tivessem utilizado. 
V Congresso Brasileiro de Informática na Educação (CBIE 2016)

Anais do XXVII Simpósio Brasileiro de Informática na Educação (SBIE 2016)

- Na versão 2.0, o dialogo com o NPC ocorre de maneira mais intuitiva (a seleção de opções é feita com auxílio do mouse); a arquitetura de comunicação utilizada é Cliente-Servidor (e todos os arquivos estão disponíveis na web, evitando que o docente se envolva com esta parte técnica); a linguagem de programação utilizada foi C\# (mais eficiente e atual); a engine que gerou a GUI foi a Unity3D 5.0 (cujo uso educacional é liberado e gratuito), e; a coleta de dados foi facilitada uma vez que o docente recolhe os arquivos na interface do seu próprio ambiente de jogo/controle (centralizada).

No caso da Versão 1.0 um dos problemas era a dificuldade de criar a conexão entre os computadores tendo em vista que havia a necessidade de digitar o endereço de IP da máquina do professor e ainda ter acesso administrador em todos os computadores, o que não é a realidade da maioria das escolas. Outro problema era a necessidade de salvar os arquivos manualmente, em cada computador, e a integração com novas ferramentas também era difícil já que era um ambiente de desenvolvimento antigo e pago.

O Unity se mostrou fácil de utilizar quanto a criar uma conexão de salas hosts, porém também teve problemas de conexão entre cliente e host em algumas redes distintas, mas no caso de uma sala de aula onde todos os computadores estão na mesma rede funcionou em todos os testes realizados. Outra facilidade encontrada foi $o$ gerenciamento de câmera, gerenciamento de colisão, sincronização de personagens que foram relativamente fácil, apesar de que a criação das texturas e animação serem mais laboriosas já que são feitas em tempo de execução e o Unity está preparado para fazer estas coisas em tempo de desenvolvimento.

Para permitir a construção da versão 2.0, um estudo detalhado da estrutura do arquivo resultante do Módulo de Autoria foi necessário. Com base neste foi escrito o código que faz a leitura desse arquivo por parte do Unity: este algoritmo lê os dados e cria os objetos correspondentes, com as devidas ligações e retorna tudo o que foi lido como um único objeto. Esta foi uma das fases mais críticas do projeto já que os tipos boleano e String gravados no arquivo são incompatíveis com as funções de leitura de booleano e String do C\#. Para o problema da String foi feita a leitura em vetores de bytes e depois decodificado para String, no caso do booleano a leitura também foi feita em bytes mas no caso de valores TRUE ainda apresenta problemas.

Para a importação dos mapas que foram produzidos na ferramenta Tiled Map Editor (http://www.mapeditor.org/) e utilizam o formato tmx, foi utilizada a ferramenta Tiled2Unity (http://www.seanba.com/Tiled2Unity). Esta importação é feita em tempo de desenvolvimento e o ideal era que fosse feita em tempo de execução, para permitir que o professor adicione novos mapas.

Para a avaliação da ferramenta uma professora desenvolveu um jogo para a disciplina de "Empreendedorismo". Esse jogo já foi testado em uma aula utilizando a versão 1.0 do Modulo de Execução, e depois esse mesmo teste foi repetido com a versão 2.0. A Figura 3 e a Figura 4 mostram a interface das versões 1.0 e 2.0, respectivamente, para o mesmo jogo/conteúdo. 
V Congresso Brasileiro de Informática na Educação (CBIE 2016)

Anais do XXVII Simpósio Brasileiro de Informática na Educação (SBIE 2016)

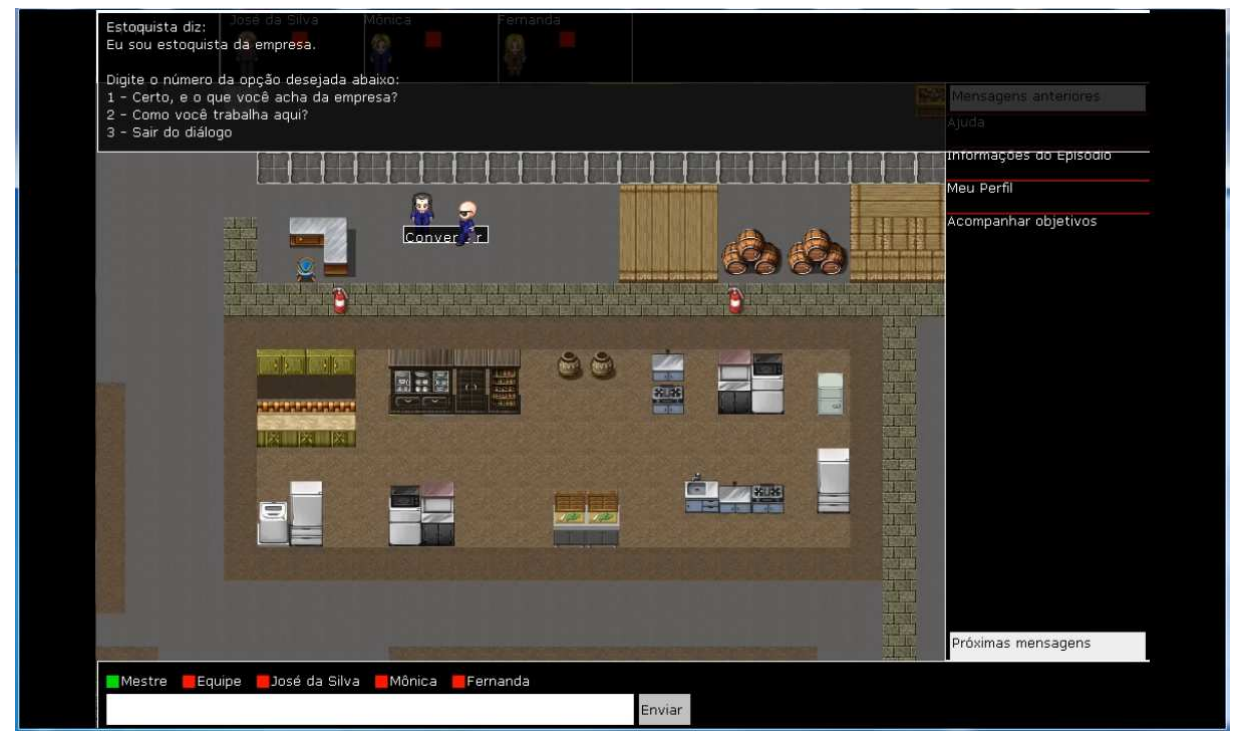

Figura3. Versão 1.0 do Modulo de Execução.

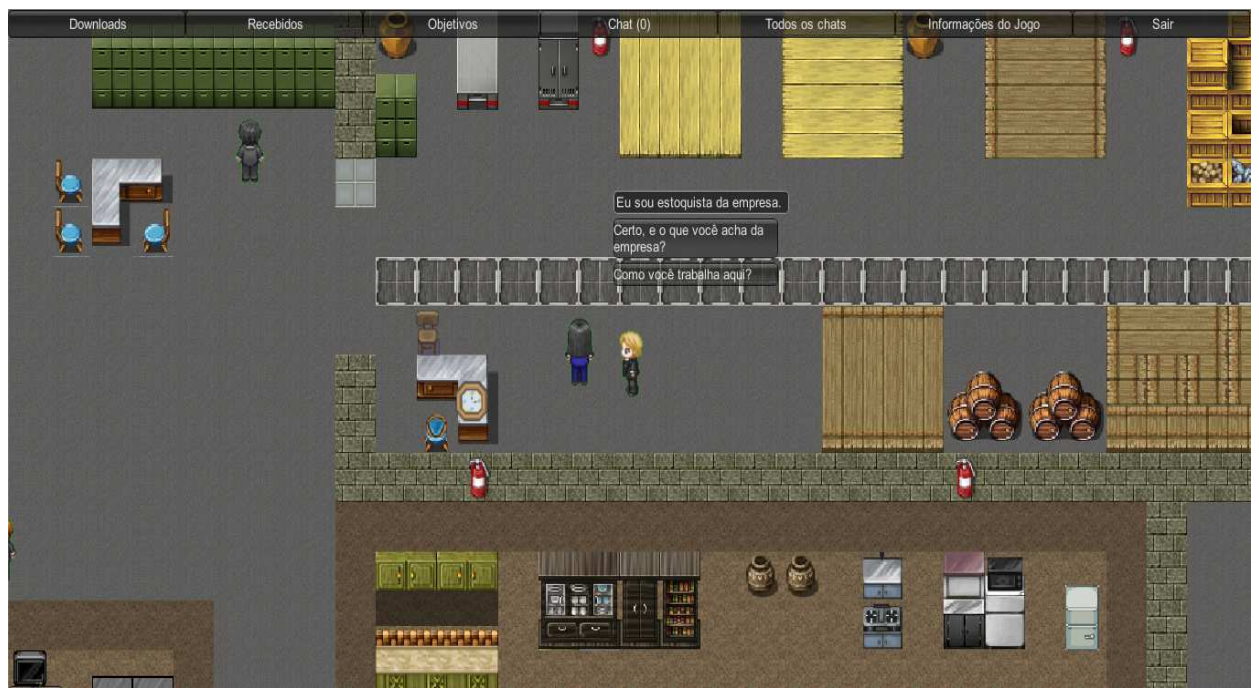

Figura4. Versão 2.0 do Modulo de Execução.

Em termos gráficos a diferença mais considerável foi na maneira com que o jogador interage com os NPCs na versão 1.0 a interação é feita por teclado, já na versão $2.0 \mathrm{o}$ jogador interage com o mouse.

\section{Resultados.}

Para avaliar a usabilidade do Modulo de Execução foram utilizados o mesmo jogo e os mesmos métodos em ambas as versões. O teste foi realizado em uma turma de 20 estudantes na versão 1.0 e durou cerca de 1 hora e 15 minutos, e 22 estudantes na versão 2.0, e durou cerca de 1 hora e 40 minutos. Ao final os estudantes responderam a um questionário de satisfação em relação ao uso do Modulo de Execução. Neste questionário os jogadores puderam dar respostas de 1 a 5 para cada questão onde, quanto mais alta a pontuação melhor. A Tabela 1 mostra as questões do questionário de satisfação, classificadas em aspectos pedagógicos e aspectos técnicos. 
V Congresso Brasileiro de Informática na Educação (CBIE 2016)

Anais do XXVII Simpósio Brasileiro de Informática na Educação (SBIE 2016)

O Gráfico1 mostra os resultados dos aspectos pedagógicos da versão 1.0 (primeiras barras, em azul, obtidas de [Pessini 2008]) em comparação com os resultados obtidos no questionário de satisfação da versão 2.0 (barras em vermelho).

\begin{tabular}{|c|c|}
\hline Aspectos & Questões \\
\hline 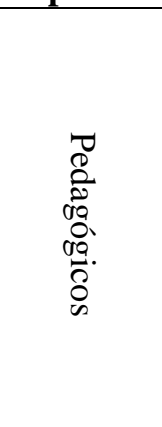 & $\begin{array}{l}\text { A. A ferramenta auxiliou o seu trabalho no decorrer da disciplina? } \\
\text { B. Você acha que conseguiu absorver o conteúdo da disciplina utilizando o RPG } \\
\quad \text { digital? } \\
\text { C. A disposição das informações (NPC, mensagens, etc) no ambiente é clara, lógica e } \\
\text { organizada? } \\
\text { D. O RPG digital permitiu com que você fizesse suas atividades de aprendizagem de } \\
\quad \text { forma organizada? } \\
\text { E. A sequência da apresentação do ambiente fez com que o jogo se desenvolvesse de } \\
\quad \text { uma forma clara? } \\
\text { F. A equipe realizou reuniões no RPG digital com frequência? }\end{array}$ \\
\hline $\begin{array}{l}\text { ㄹ. } \\
\stackrel{\Omega}{B} \\
\stackrel{8}{\delta}\end{array}$ & $\begin{array}{l}\text { G. A ferramenta atendeu às suas expectativas? } \\
\text { H. Como você utilizou as funcionalidades do RPG digital? } \\
\text { I. Qual seu sentimento em relação ao tempo de resposta da ferramenta? } \\
\text { J. Você acha que a ferramenta conseguiu integrar sistemas computacionais, educação } \\
\quad \text { e jogos de estratégia? } \\
\text { K. Os recursos do RPG digital influenciaram na vontade de jogar? } \\
\text { L. A apresentação do RPG digital foi atrativa? } \\
\text { M. O treinamento inicial no RPG digital foi suficiente? } \\
\text { N. A ferramenta auxiliou a colaboração entre os personagens do grupo no decorrer da } \\
\quad \text { disciplina? }\end{array}$ \\
\hline
\end{tabular}

Tabela 1: Questões classificadas em aspectos técnicos e pedagógicos adaptada de Pessini (2015).

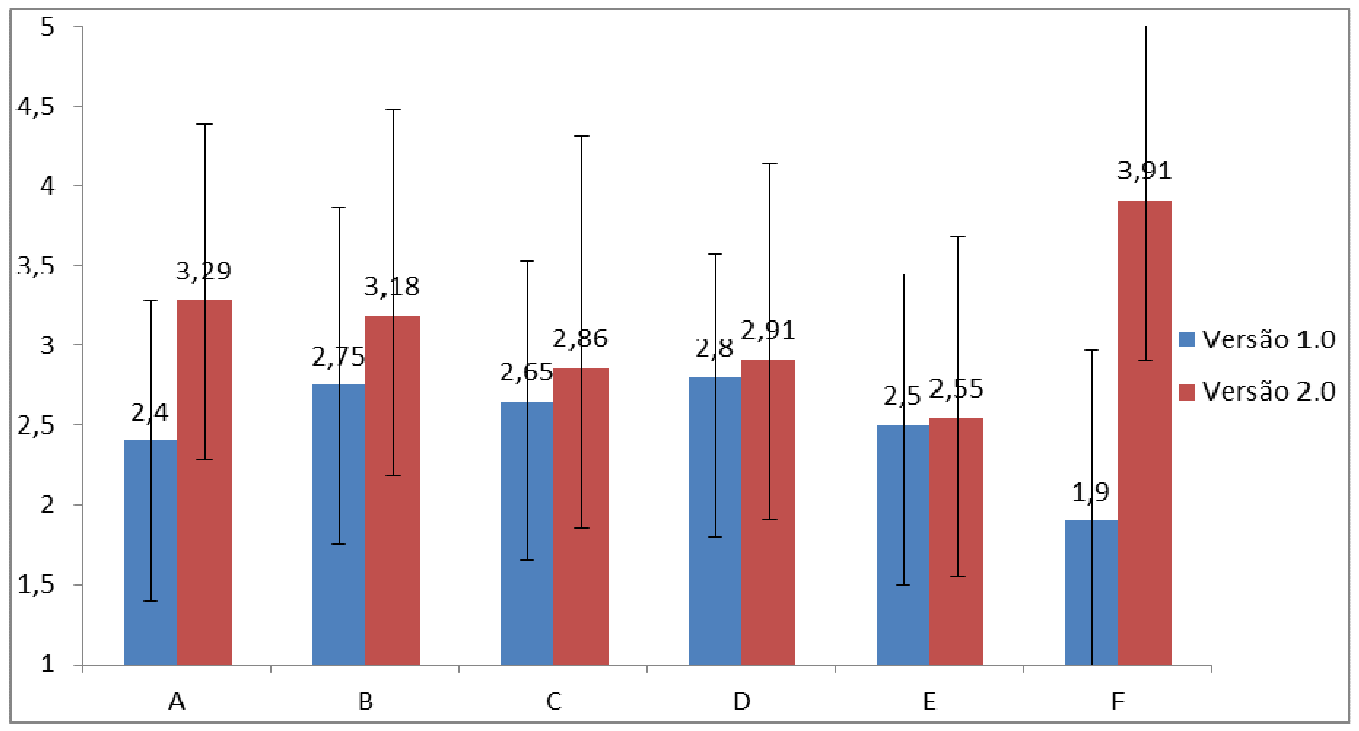

Gráfico 1: Aspectos pedagógicos de ambas as versões do ME.

O Gráfico 2 apresenta os aspectos técnicos relativos ao modulo de execução versão 1.0 em comparação com o modulo de execução da versão 2.0. 


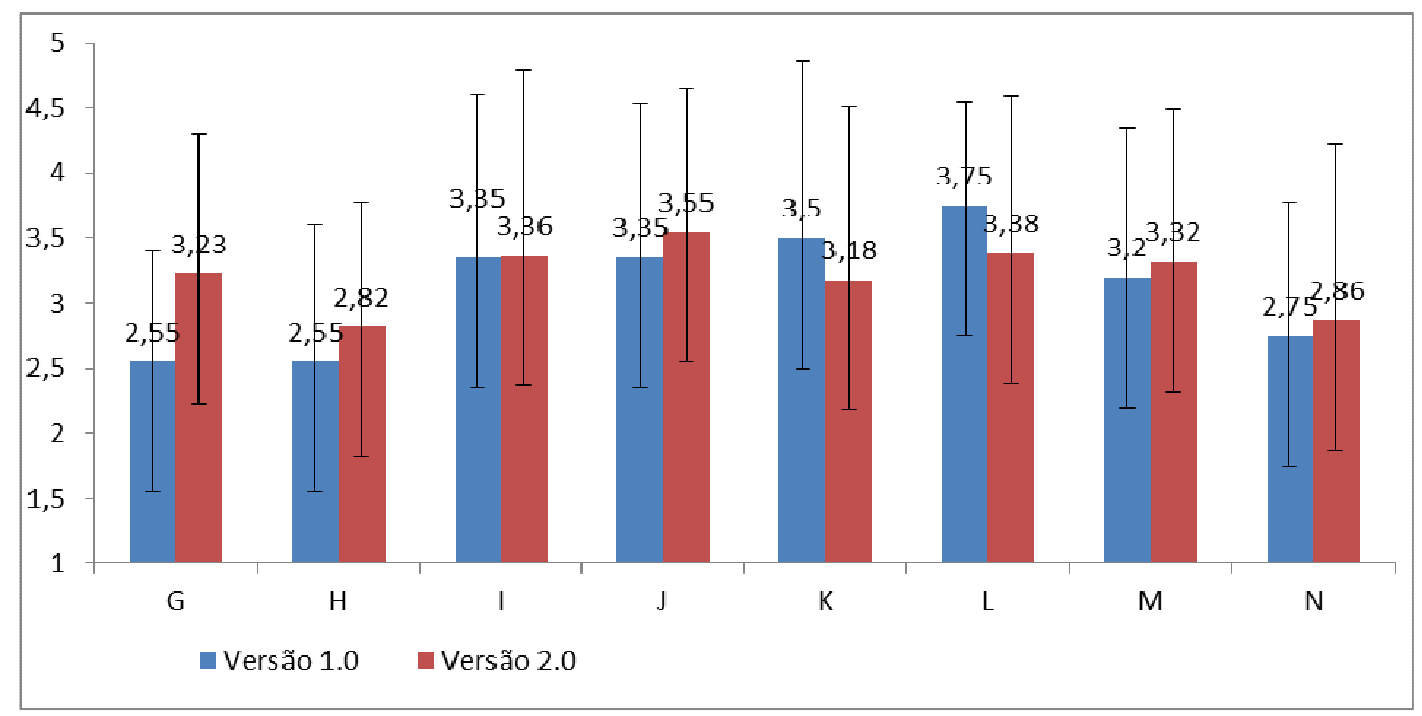

Gráfico 2: Aspectos técnicos de ambas as versões do ME.

\section{Discussão}

As maiores diferenças em favor da versão 2.0 foram na questão $F$ (reuniões da equipe de estudantes usando o ambiente do jogo RPG digital) e em menor escala na questão A (o quanto o jogo ajudou no estudo) os demais resultados foram praticamente iguais. Um dos motivos que levou a grande diferença na questão $\mathrm{F}$ foi a melhoria do chat. $\mathrm{E}$, na questão $\mathrm{A}$, diversos aspectos podem ter influenciado para uma melhor avaliação como a própria melhoria do chat, um ambiente mais interativo e visualmente mais agradável e, principalmente, as falhas que ocorreram no teste realizado com a versão 1.0 que impossibilitaram a conclusão do jogo pelos estudantes.

A média das respostas dos aspectos pedagógicos ficou em 2,55 na versão 1.0 e 3,11 na versão 2.0 (a nota no meio da escala é 3,0). Este resultado é curioso pois, o conteúdo não foi alterado entre as versões. Isto sugere que os aspectos técnicos podem ter influenciado a avaliação dos aspectos pedagógicos (felizmente para melhor uma vez que a versão 2.0 é melhor). Esta suposição, entretanto, não encontra amparo nos dados da avaliação técnica exarada pelos alunos. Uma diferença entre o experimento da versão 1.0 para a versão $2.0 \mathrm{O}$ acompanhamento da professora autora quando da aplicação da versão 2.0 permitu concluir que a participação direta do docente é fundamental para o processo de aprendizado, independente até das questões tecnológicas.

Vale ressaltar que houve um acompanhamento completo por parte da professora autora do jogo. Foi a primeira vez que a professora viu o "seu" jogo sendo utilizado efetivamente em sala de aula, na disciplina para a qual ele fora projetado. Este acompanhamento ocorreu pela primeira vez e esta reconheceu que algumas das dúvidas exaradas pelos estudantes, estavam mais relacionadas com a estrutura do conteúdo que ela planejou do que do funcionamento do jogo RPG em sí. Isto significa que a avaliação por parte do docente, do jogo por completo e pronto, ao final, deve ser uma etapa a ser incluida em qualquer metolodologia de desenvolvimento para garantir os aspectos tecnológicos e pedagógicos.

Ainda, notou-se que a duração da exploração do jogo por parte dos estudantes requereu todo o período de aula disponível (uma hora e quarenta minutos). Desta forma, haveria 
V Congresso Brasileiro de Informática na Educação (CBIE 2016)

Anais do XXVII Simpósio Brasileiro de Informática na Educação (SBIE 2016)

a necessidade de (a) dividir o jogo em etapas menores - o que poderia levar a um aumento geral do tempo de jogo ou, (b) diminuir a proposta do jogo original para caber no tempo disponível - o que poderia levar a uma diminuição do conteúdo a ser ministrado.

\section{Conclusão}

O desenvolvimento de ferramentas para o próprio professor ser autor de recursos computacionais para suas aulas colabora com a popularização do uso da informática na educação. Ferramentas de Autoria (FA) são os sistemas que se encaixam nesta classe. FA voltadas a produção de jogos digitais sérios (para conteúdos disciplinares específicos e projetados com fins educacionais desde o início) são escassos. Propostas de FA para jogos têm surgido na literatura. A RPG4ALL é uma dessas FA que foi concebida para facilitar a produçao de jogos digitais do tipo RPG. Esta ferramenta mostrou-se adequada quando avaliada por professores de disciplinas variadas. Este trabalho avaliou o resultado do uso desta FA: o jogo digital educacional do tipo RPG. No caso, um jogo voltado para o ensino de conceitos básicos da disciplina de Empreendedorismo.

A avaliação de usabilidade, nos aspectos pedagógicos e técnicos, efetuada por 42 estudantes que utilizaram o jogo mostrou que os aspectos pedagógicos do jogo na versão 2.0 foram melhores que os da versão 1.0 sendo que o único diferencial entre as versões, fora os aspectos tecnológicos (cujos estudantes avaliaram como equivalentes), foi a presença e participação direta da professora autora do conteúdo e estrutura do jogo.

Conclui-se que, independente do aporte tecnológico em que se apresenta o artefato educacional (um jogo digital RPG), o envolvimento do professor é fundamental. Não só no momento da autoria como no momento da aplicação do artefato, pois este consegue dirimir dúvidas e vislumbrar o potencial do artefato criado. $\mathrm{O}$ envolvimento do professor autor nas primeiras experiências de uso efetivo do artefato também se mostrou fundamental pois o mesmo pode avaliar na prática a relação entre o que fora projetado enquanto recurso pedagógico e a prática do uso do artefato perante as restrições de tempo, número de alunos, controle da sala e, até, estrutura do jogo/conteúdo.

\section{Agradecimentos}

Este trabalho foi realizado durante uma bolsa de estudos do Programa de Estágio Sênior no Exterior - CAPES Proc. N ${ }^{\circ}$ BEX 2539 / 15-2 (Brasil) e à UDESC pela Bolsa de Iniciação Científica pelo programa PROBIC.

\section{Referencias}

ARAÚJO, R. M. (2006) Do RPG de mesa à narrativa interativa nos jogos digitais. Trabalho de Graduação. Universidade Federal de Pernambuco.

CORRÊA, A. G. D. et al. (2008) GenVirtual: Um jogo musical para reabilitação de indivíduos com necessidades especiais. In: Revista Brasileira de Informática na Educação. v.16. n.1. p. 1-9.

DORMANS, J. (2006). On the Role of the Die: A brief ludologic study of pen-andpaper roleplaying games and their rules. Game Studies, v. 6 n. 1. 
V Congresso Brasileiro de Informática na Educação (CBIE 2016)

Anais do XXVII Simpósio Brasileiro de Informática na Educação (SBIE 2016)

DORMANS, J. (2012) The Efectiveness and Efciency of Model Driven Game Design. In: Lecture Notes in Computer Science. v.7522, p.542-54.

FRIAS, E. R. (2009) Jogo das representações (RPG) e aspectos da moral autônoma. Mestrado, Universidade de São Paulo.

GONÇALVES, D. A.; FERREIRA, M. G. G. (2012) Fighting dragons or saving a princess: what is a game? In: Proceedings of XI Simpósio Brasileiro de Jogos e Entretenimento Digital. p.184-188.

GRANDO, R. C. (1995). O jogo e suas possibilidades metodológicas no processo ensino-aprendizagem da matemática Mestrado em Educação. Universidade Estadual de Campinas.

GRANDO, A., \& Tarouco, L. M. R. (2008). O uso de jogos educacionais do tipo RPG na educação. RENOTE, v.6 n.1.p.1-10.

HAGUENAUER, C. J., CARVAlHO, F., VICTORINO, A. L. Q., LOPES, M., \& Cordeiro Filho, F. (2008). Uso de Jogos na Educação Online: a Experiência do LATEC/UFRJ. Revista EducaOnline, v.2, p. 1-11.

MAIKE, V. R. M. L.; MIRANDA, L. C.; BARANAUSKAS, M. C. C. (2011) Investigando sobre Requisitos para um Jogo de RPG com Professores de uma Escola Pública de Ensino Fundamental. Simpósio Brasileiro de Informática na Educação.

MEHM, F. (2010) Authoring serious games. In: Proceedings of the Fifth International Conference on the Foundations of Digital Games. New York, NY, USA, p.271-273.

MICHAEL, D.; CHEN, S. (2006) Serious Games: Games that Educate Train and Inform. Boston: Thomson Course Technology.

PESSINI, A. (2015) Uma ferramenta de autoria para o desenvolvimento de Jogos Sérios do gênero RPG. Dissertação de Mestrado em Computação Aplicada. Universidade do Estado de Santa Catarina.

SCHMIT, W. L. (2008) RPG e Educação: Alguns apontamentos Teóricos. Dissertação de Mestrado, Universidade Estadual de Londrina, Londrina.

TANG, S. HANNEGHAN, M.; CARTER, C. (2013). A Platform Independent Game Technology Model for Model Driven Serious Games Development. The Electronic Journal of e-Learning, v.11, n.1, p.61-79.

TORRENTE, J.; VALLEJO-PINTO, J.A.; MORENO-GER, P.; FERNÁNDEZMANJÓN, B. (2011) Introducing Accessibility Features in an Educational Game Authoring Tool: The <eAdventure> Experience. In: 11th IEEE International Conference on Advanced Learning Technologies. p.341-343.

ZARRAONANDIA, T.; DÍAZ, P. \& AEDO, I. (2012) A Modular approach to support the Multidisciplinary Design of Educational Game Experiences. In: Proceedings of the 19th International Conference on Neural Information Processing. p.560-567. 